\title{
Bovinocultura de corte e SAN: percepção de sustentabilidade de agentes da cadeia
}

\author{
Natália Salaro Grigol ${ }^{1}$, Mariane Crespolini ${ }^{2}$, Marianne Tufani ${ }^{3}$, João Paulo Franco da \\ Silveira $^{4}$ e Caio Augusto de Souza Mello Monteiro ${ }^{5}$
}

\begin{abstract}
A bovinocultura de corte e o consumo de carne bovina têm grande relevância para a garantia da segurança alimentar e nutricional (SAN) no Brasil. No entanto, a baixa produtividade dos sistemas produtivos está associada a impactos ambientais - o que, por consequência, também desperta questionamentos acerca da SAN. Tendo em vista o quadro conceitual da Nova Economia Institucional, este estudo teve como objetivo identificar a percepção de agentes da bovinocultura de corte de Mato Grosso, Mato Grosso do Sul e Pará em relação aos desafios da atividade e da sustentabilidade da produção, por meio de entrevistas não-estruturadas. Os resultados apontam que o aumento de produtividade é percebido como o maior e mais imediato desafio da cadeia. A falta de visão de longo prazo, aversão ao risco e grande cautela dos pecuaristas em realizar investimentos foram citados como obstáculos. Sistemas de integração lavoura-pecuária ou lavoura-pecuária-floresta foram considerados tendência para a incorporação de sustentabilidade na produção. Entretanto, para os entrevistados, a busca pela sustentabilidade se dá, primeiramente, na esfera econômica, ficando a questão ambiental em segundo plano. Ainda assim, as sinergias produtivas dos sistemas de integração podem ser "portas de entrada” para o debate da sustentabilidade em suas múltiplas dimensões.
\end{abstract}

Palavras-chave: Bovinocultura de corte, sistemas produtivos, sustentabilidade, Segurança Alimentar e Nutricional.

\section{Beef catle and SAN: perception of the sustainability of agents of the chain}

Cattle breeding and beef consumption are of great importance for ensuring food and nutritional security in Brazil. However, the low productivity of production systems is associated with environmental impacts - which, consequently, also raises questions about the food and nutritional security. Based on the New Institutional Economy framework, this study aimed to identify the cattle breeding agents' perception regarding to activity challenges and production sustainability in Mato Grosso, Mato Grosso do Sul and Pará by using unstructured

${ }^{1}$ Universidade Estadual de Campinas (Unicamp) e Centro de Estudos Avançados em Economia Aplicada (Cepea). Endereço para correspondência: Av. Centenário no 1.080, Piracicaba, São Paulo. Contato: (19)991458355.E-mail: natalia.grigol@gmail.com

2 Universidade Estadual de Campinas (Unicamp) e LMH Consultoria. Contato: (66)96606269. E-mail: macrespolini@gmail.com

${ }^{3}$ Instituto Mato-Grossense de Economia Agropecuária (Imea). Endereço para correspondência: Rua Engenheiro Edgard Prado Arze, no 0, Edifício Famato, CPA, Cuiabá, Mato Grosso. Contato: (65) 96242069.E-mail: marianne.tufani1@gmail.com

${ }^{4}$ DSM/Tortuga. Endereço para correspondência: Rua Guanabara no 160, Sinop, Mato Grosso. Contato: (66) 96114370. E-mail: jpfsrural@gmail.com

${ }^{5}$ Escola Superior de Agricultura "Luiz de Queiroz". Centro de Estudos Avançados em Economia Aplicada (Cepea). Endereço para correspondência: Av. Centenário no 1.080, Piracicaba, São Paulo. Contato: (16)991548177.E-mail: caiomonteirofsc@gmail.com 
interviews. The results indicate that the increase in productivity is perceived as the biggest and most immediate challenge for beef cattle chain. The lack of long-term vision, risk aversion and great caution of cattle ranchers in making investments were cited as obstacles. Systems of crop-livestock integration or crop-livestock-forest were considered as a trend for the incorporation of sustainability into production. However, for the interviewees, sustainability is primarily understood in its economic dimension, whereas environmental issues are in the background. Nevertheless, productive synergies of integration systems can be "gateways" to the sustainability debate in its multiple dimensions.

Keywords: Beef cattle, productive systems, sustainability, Food and Nutritional Security.

\section{INTRODUÇÃO E OBJETIVOS}

A bovinocultura de corte é uma das principais atividades do agronegócio brasileiro. Sua participação no Produto Interno Bruto (PIB) do agronegócio, em 2017, foi de 13,6\%, enquanto que no PIB nacional representou 3\% ${ }^{[1]}$.

De acordo com United States Department of Agriculture (USDA), foram produzidas $9.550 \mathrm{mil}$ toneladas de carne bovina em 2017, o que representou $15 \%$ da produção mundial naquele ano. De acordo com dados do USDA, o Brasil é o segundo maior produtor de carne bovina do mundo, atrás apenas dos Estados Unidos. No entanto, o País é o maior exportador de carne bovina, tendo exportado 1,85 milhões de toneladas em 2017. Esse volume, no entanto, não se compara à própria demanda interna brasileira. Cerca de $80 \%$ da produção nacional é absorvida pelo mercado doméstico, o que faz do Brasil o 3 o maior consumidor de carne bovina do mundo[2].

Segundo Silva[3], a alimentação brasileira, marcada por regionalidades em função da diversidade dos fatores ambientais e do histórico de ocupação dos territórios no Brasil, possui um denominador comum no "tripé" arroz, feijão e uma "mistura", se referindo a uma carne. O maior consumo per capita ocorre para as carnes de frango e a bovina, segundo dados da Associação Brasileira de Proteína Animal (ABPA)[4].

No entanto, é interessante observar que o consumo de carne bovina é o de maior preferência, sendo o alimento mais procurado quando ocorre elevação da renda doméstica[5]. Dessa forma, a carne bovina é um alimento importante na dieta da população, contribuindo para a segurança alimentar e nutricional das famílias.

O conceito de segurança alimentar e nutricional (SAN), definido segundo a Lei no 11.346 de 15 de setembro de $2006\left[{ }^{[6]}\right.$, refere-se ao direito de garantia de:

[...] acesso regular e permanente a alimentos de qualidade, em quantidade suficiente, sem comprometer o acesso a outras necessidades essenciais, tendo como base práticas alimentares promotoras de saúde que respeitem a diversidade cultural e que sejam social, econômica e ambientalmente sustentáveis.

Como enfatizado por Custódio[7], o conceito é amplo, ao passo que envolve aspectos relacionados tanto à oferta quanto à demanda, como produção, desenvolvimento sustentável, abastecimento, comercialização, aproveitamento e aquisição de alimentos.

Considerando que até 2050, a população mundial deva atingir a impressionante marca de 9 bilhões de pessoas, a demanda por alimentos deve aumentar sobremaneira, principalmente nos países em desenvolvimento, também em função da intensificação dos processos de industrialização, aumento do número de pessoas residindo em áreas urbanas e elevação do poder médio de compra dos consumidores ${ }^{[8]}$. A expansão do modo de vida urbano-industrial ocidental e da dieta ocidentalizada, caracterizada pela prevalência de alimentos industrializados, é questão-chave neste cenário.

A demanda mundial de carne bovina deve se elevar a nível global, exigindo dos países maiores volumes de produção. Esta é uma das mais 
poderosas tendências na agricultura mundial, ao passo que estes alimentos, historicamente, situavamse em posições periféricas na alimentação humana, mas, progressivamente, têm ocupado posições centrais nas dietas das populações de diversos países ${ }^{[0]}$.

Nesse contexto, destaca-se o papel estratégico do Brasil em fornecer carne bovina, devido ao elevado potencial de aumento da produção com custos competitivos em relação aos outros países ${ }^{[10]}$. Em contrapartida, o fato da bovinocultura de corte brasileira se basear em sistemas produtivos extensivos com uso limitado de tecnologias e baixa produtividade[11] desperta preocupações acerca da questão ambiental, sobretudo pela dependência do aumento de área para se viabilizar economicamente - o que, por consequência, também desperta questionamentos acerca da garantia de SAN.

Para Herrero e Thorton[12], uma vez que a atividade pecuária está relacionada a importantes impactos ambientais, o expressivo crescimento da demanda por proteína animal impõe o enorme desafio de garantir a oferta de carne bovina no atual sistema alimentar global.

Diante dos diversos problemas ambientais advindos da exploração insustentável dos recursos naturais, faz-se a ligação entre a sustentabilidade ambiental e a segurança alimentar e nutricional.

Para Michelini[9], ao mesmo tempo em que a produção de alimentos gera as mudanças ambientais globais, ela também é impactada pelos efeitos dessas mudanças. Não se trata, pois, apenas de aumentar a quantidade de comida, mas também de lidar com os desafios de se produzir alimentos de uma forma ambientalmente e socialmente sustentável.

A preocupação com o desenvolvimento econômico atrelado à preservação ambiental foi registrada no Relatório Brundtland, a partir do conceito de desenvolvimento sustentável. Este, por sua vez, é entendido como o desenvolvimento que satisfaz as necessidades da atual geração sem, contudo, comprometer as necessidades das gerações futuras [13].
O Guia Alimentar da População Brasileira ${ }^{[14]}$ apresenta um debate acerca do tema. Afirma que a padrões saudáveis de alimentação dependem de sistemas alimentares que protejam e respeitem o ambiente natural de onde os alimentos são obtidos. As recomendações se baseiam também nos efeitos que as escolhas alimentares têm sobre os recursos naturais e sobre a biodiversidade das espécies, indicando o consumo de alimentos que não ameaçam a alimentação das futuras gerações. No caso da carne bovina, o Guia Alimentar ${ }^{[14]}$ ressalta algumas externalidades da produção, como o uso da água. Além disso, reforça a importância de uma dieta diversificada e equilibrada, com a ingestão de outros alimentos, bem como hábitos de vida mais saudáveis.

É fato que escolhas alimentares dos consumidores representam importantes decisões ambientais, mas Tobler, Visschers e Siegrist ${ }^{15]}$ constataram que os motivos ambientais, por si só, podem não ser a estratégia de persuasão mais forte para incentivar um perfil de consumo mais ecológico.

Desse modo, assegurar uma produção mais sustentável é um desafio de longo prazo que precisa ser encarado independente da demanda para tal. $\mathrm{O}$ consumo de carne bovina deve se elevar nos próximos anos e, por esse motivo, é inegável a necessidade latente de mudanças e adequações aos sistemas de produção pecuária com maior orientação para a sustentabilidade e conversão eficiente dos recursos naturais.

Dentre as possíveis alternativas, destacam-se os sistemas integrados de produção, como a integração lavoura-pecuária (ILP) e a integração lavoura-pecuária-floresta (ILPF). A adoção desses sistemas, embora ainda limitada, contribui para o aumento de produtividade por hectare e para a recuperação das áreas degradadas, por meio de sistemas rotacionados de culturas que, além de elevarem a qualidade do solo, permitem sua exploração econômica durante todo o ano[16].

Diante desse contexto, o objetivo deste estudo foi explorar a percepção de agentes da cadeia de bovinocultura de corte quanto aos desafios futuros da atividade, principalmente no que se refere à questão de sustentabilidade. $\mathrm{O}$ estudo também explora como o conceito de 
sustentabilidade é entendido pelos agentes e sua relação com a tomada de decisão. Uma das hipóteses é de que a adoção de sistemas integrados de produção (ILP/ILPF) esteja se fortalecendo em consequência da busca por maior sustentabilidade na produção.

\section{A bovinocultura de corte e a sustentabilidade}

Dois dos maiores historiados do Brasil, Prado Jr. ${ }^{[17]}$ e Furtado[18], consideram a expansão da bovinocultura de corte a atividade mais importante na ocupação do território brasileiro. Isto foi de extrema relevância para a soberania e economia nacional, pois garantiu território e foi a atividade inicial de muitas economias regionais.

O movimento itinerante de expansão é, portanto, característico da pecuária bovina brasileira e foi fomentado pelo quadro institucional brasileiro, justamente visando a ocupação e integração econômica regional das regiões de fronteira. Por outro lado, a dinâmica expansionista também estruturou um modelo de exploração extensivo e de baixa produtividade [19].

Com a menor disponibilidade de terras e com o aumento da competição entre as culturas, a atividade tende a perder viabilidade. O cultivo de grãos, por exemplo, proporciona maior rentabilidade por área do que a pecuária. Assim, o plantio de soja tende a ocupar áreas de pastos degradados, enquanto a bovinocultura de corte se expande para outras áreas ${ }^{[19,20]}$.

Para Dias-Filho[11], o problema se concentra no fato da produção brasileira se basear em sistemas extensivos, com manejo inadequado de pastagens e uso limitado de tecnologias. De tal modo que o autor estima que entre $50 \%$ a $70 \%$ das pastagens do Brasil apresentam algum grau de degradação ambiental. Existe uma tradição na pecuária brasileira de baixo investimento para a formação e manejo de grande parte das pastagens brasileiras, resultante do relativo sucesso econômico mesmo sem o uso intensivo de insumos, tecnologia e mão de obra, o que possibilita que a atividade seja implantada e conduzida em condições de infraestrutura deficiente[21].

É preciso ponderar que o modelo de produção de carne bovina extensivo está associado a fenômenos como: degradação, compactação e erosão do solo; assoreamento de rios, nascentes e corpos d'água; redução da biodiversidade por conta da destruição de biomas naturais e da formação de monocultivo; e emissões de gases de efeito estufa ${ }^{20,}$ 22,23,24]. O impacto ambiental mais debatido é o desmatamento, principalmente na Amazônia e Cerrado $[19,20]$.

O contexto histórico e os incentivos governamentais, lentamente, construíram instituições que acabam por legitimar esse modelo de bovinocultura de corte extensiva no Brasil. Existe, portanto, uma estrutura estruturante dessa realidade, que pode ser compreendida sob a ótica do quadro conceitual da Nova Economia Institucional (NEI), que aponta que:

\footnotetext{
As instituições são as restrições impostas pelos humanos nas suas interações. Consistem em regras formais (constituições, leis, estatutos, regulamentos e direitos comuns) e informais (convenções, normas, e códigos de conduta). As instituições definem, (...), as combinações de risco e recompensa que podem ser construídos com os recursos disponíveis em uma economia [25].
}

Enquanto as instituições são as regras, as organizações são os jogadores e a interação entre elas geram as mudanças institucionais. Outro destaque é que, as escolhas individuais dependem de fatores culturais e cotidianos, o que significa que, indivíduos com históricos diferentes interpretarão de forma distinta a mesma situação. Os resultados não são, portanto, escolhas racionais e perfeitas[25].

Nesse sentido, a produtividade, assim como a rentabilidade da bovinocultura de corte poderiam ser muito mais expressivas, se houvessem objetivos comuns e convergência de ações para intensificá-la. Em outras palavras, transformações no paradigma produtivo seriam possíveis se, institucional e organizacionalmente, a atividade se estruturasse sob uma perspectiva mais sustentável, nos termos propostos pelo Relatório Brundtland ${ }^{[13]}$.

Conforme destacado por Santos et al.[2], o fato da bovinocultura de corte ser uma atividade de baixo risco estimula a permanência de pecuaristas mesmo que a rentabilidade seja baixa. Além disso, ressalta-se que por muitas décadas, o boi foi um 
importante ativo para compensar os efeitos da inflação descontrolada.

Recentemente, o quadro econômico e institucional tem mudado. A política de estabilização a partir de 1994 pode ser considerada um dos impactos mais relevantes. Enquanto o consumidor se beneficiou com a redução dos preços dos alimentos, produtores rurais viram sua rentabilidade cair dramaticamente. No caso da bovinocultura de corte, essas mudanças exigiram adaptação dos produtores, já que o boi deixou de ser reserva de valor ${ }^{[27]}$. Isso se traduziu em necessidade de elevar os investimentos para aumento de produtividade. Martha Jr. et al.[28] demonstram que, a partir de 1985, são os ganhos de produtividade, e não a expansão da área produtiva, que explicam o aumento da produção da bovinocultura de corte.

Mesmo com os avanços, há muito ainda a ser feito, na medida em que a produtividade das pastagens cultivadas brasileiras atinge apenas $34 \%$ de seu potencial. Estima-se que um aumento na produtividade entre 49 e $52 \%$ deste potencial poderia suprir as demandas para as cadeias de proteína animal, grãos, produtos madeireiros e biocombustíveis, sem a necessidade de expandir área, pelo menos até 2040[29].

Diante dessas necessidades, surge, na década de 70, o conceito de Produção Integrada[30]. Destacamse a integração lavoura-pecuária (ILP) e lavourapecuária-floresta (ILPF), as quais são caracterizadas pela diversificação, rotação, combinação ou sucessão planejada das atividades agrícolas e pecuárias dentro da propriedade rural, constituindo um mesmo sistema que beneficia todas as atividades desenvolvidas.

Os sistemas integrados possuem diversas vantagens. $\mathrm{O}$ solo pode ser aproveitado economicamente durante todo o ano. Como o produtor possui mais de uma cultura e receitas em períodos distintos do ano, a diversificação da produção e comercialização reduz o risco climático. Também ocorre a redução de custos de produção por conta da otimização do uso de máquinas, equipamentos, insumos e mão de obra ao longo do ano e do menor uso de defensivos agrícolas (diminuição na incidência de pragas, doenças e plantas

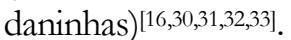

Além disso, com a introdução de capins em determinados períodos nas áreas de lavoura (Sistema de Plantio Direto na palha mais eficiente), o uso de fertilizantes também é menor. Ademais, a produção de grãos pode ser utilizada para a alimentação dos animais e, no caso da ILPF, a sombra das árvores proporciona conforto térmico ao rebanho. Outra vantagem é a recuperação produtiva de áreas já desmatadas, já que a correção de solo usada para a agricultura minimiza o risco de erosão. Ao mesmo tempo, a necessidade de abertura de novas áreas de pastagens se reduz e a produção por hectare aumenta[16,30,31,32,33].

Embora os sistemas integrados apresentem resultados favoráveis à produção e ao meio ambiente, sua adoção e difusão ainda são limitadas, principalmente pela dificuldade em captar recursos para financiamento e pela maior complexidade do planejamento e controle dos projetos, fatores que indicam a necessidade de inovação em gestão e de políticas públicas mais efetivas ${ }^{[3]}$.

Crespolini et al $\left[{ }^{[34]}\right.$ relataram, em estudo de caso, as dificuldades de acesso de crédito e resistência à implementação da ILP em uma fazenda em Rondônia. O estudo, no entanto, mostra que, a partir da melhoria da gestão administrativa, os índices produtivos e econômicos se elevaram. Além disso, com a ILP, a fazenda conseguiu atender aos três pilares da sustentabilidade: do ponto de vista econômico, a rentabilidade do pecuarista aumentou em 130\%; já do ponto de vista ambiental houve a recuperação de áreas degradadas, melhora na fertilidade dos solos, retirada da monocultura; e, por fim, do ponto de vista social houve a melhoria na qualidade de vida dos trabalhadores, maior geração de emprego e renda.

Desse modo, os sistemas integrados podem ser considerados práticas sustentáveis. De acordo com a Cúpula Mundial da Organização das Nações Unidas $(\mathrm{ONU})^{[35]}$, a sustentabilidade é garantida quando são atendidos os aspectos econômicos (como o aumento de renda e produtividade), sociais (melhoria da qualidade de vida) e ambientais (práticas produtivas ambientalmente adequadas).

Nesse sentido, os sistemas integrados também se relacionam à SAN, ao passo que viabilizam a produção em quantidade e qualidade através de uma prática produtiva que é social, econômica e ambientalmente sustentáveis. Pensar os sistemas de produção de alimentos é extremamente importante 
diante do atual contexto global de crescimento populacional, aumento da urbanização, mudanças climáticas e exploração insustentável dos recursos naturais.

Dada sua amplitude e transversalidade, o conceito de sustentabilidade pode ser entendido de formas diferentes pelos atores sociais, o que pode impactar a maneira como se organizam e o ambiente institucional da bovinocultura de corte no Brasil.

É sabido que a tomada de decisão decorre de um processo complexo, fruto de influências individuais (personalidade, valores, estilo de vida), sociais, econômicas e ambientais (levando em conta, por exemplo, cultura, classe social, família e recursos disponíveis) [36]. Assim, a percepção dos agentes sobre o tema engendra sua estratégia para alocação de recursos. Nesse sentido, estudos de percepção[ ${ }^{[37]}$ podem auxiliar a identificar e explorar o posicionamento dos pecuaristas em relação à sustentabilidade e também a trabalhar os desafios associados ao tema de maneira mais assertiva. Esse entendimento é importante para fomentar discussões e transformações no ambiente institucional e organizacional da atividade.

Vale lembrar que o aprendizado, a troca de conhecimento tácito sobre sistemas de inovação (como podem ser entendidos a ILP e ILPF) e a adoção de tecnologias por produtores rurais têm uma dinâmica local e são influenciados pelas instituições e lideranças [38]. Isso significa que, os produtores mostram maior predisposição a adotar uma inovação ou tecnologia, por exemplo, após alguém de sua rede de contatos (como um vizinho, por exemplo) já ter adotado e obtido resultados satisfatórios. Assim, a percepção, opinião e comunicação entre os agentes têm o potencial de acelerar esta rede regional de adoção de tecnologias e abrir oportunidades para o rompimento com os modelos produtivos anteriores, gerando novos produtos e processos ${ }^{[38]}$. Esses, por sua vez, ajudam a consolidar um novo ambiente institucional para a atividade.

\section{MATERIAL E MÉTODOS}

Este estudo, de caráter exploratório e qualitativo, se propôs a explorar a percepção de agentes da cadeia de bovinocultura de corte dos estados de Mato Grosso, Mato Grosso do Sul e
Pará. Estes estados foram escolhidos dada sua representatividade na produção nacional.

Foram aplicadas entrevistas semiestruturadas ${ }^{[39]}$ via telefone durante outubro de 2017. As entrevistas foram iniciadas solicitando ao entrevistado que respondesse a questão: "na sua percepção, quais os desafios atuais da cadeia de bovinocultura de corte em relação à sustentabilidade?”. O objetivo desta pergunta geral e aberta era propiciar um ambiente onde o entrevistado se sentisse confortável para discorrer sobre diferentes aspectos, abordando temas relacionados à hipótese do estudo sem, contudo, enviesá-lo.

Utilizou-se amostragem não probabilística por julgamento, ou amostragem intencional[39]. Assim, foram selecionados, dentre uma vasta rede de contatos, agentes do setor experientes, que vivenciam e representam a visão do campo e que podem desempenhar papeis de liderança e/ou de influência.

Foram entrevistados 15 agentes do setor, dos quais 5 foram produtores, 3 assistentes técnicos, 2 representantes de associações, 1 veterinário, 1 vendedor de insumos pecuários e 3 pesquisadores da área. A coleta de dados foi encerrada em decorrência de saturação teórica, pela repetição das categorias de análise e de informações presentes no discurso dos entrevistados.

As entrevistas foram transcritas pelos autores. Depois da cuidadosa apreciação das informações, foram identificadas categorias de análise a partir da recorrência dos temas articulados pelos entrevistados. $\mathrm{Na}$ sequência, os autores revisaram e validaram as categorias identificadas para definir, de forma consensual, as relações observadas nos discursos dos entrevistados.

\section{RESULTADOS E DISCUSSÃO}

A análise das entrevistas permitiu identificar que o "aumento de produtividade" é percebido como o maior e mais imediato desafio da bovinocultura de corte brasileira. Para os entrevistados, para promover a sustentabilidade da atividade é preciso elevar a produtividade por área, o que diminuiria a necessidade da expansão da fronteira agrícola. Essa 
percepção, contudo, não é motivada pelas preocupações acerca dos impactos ambientais da bovinocultura de corte ou pelo discurso ambientalista em primeira instância. Os esforços para o aumento da produtividade estão vinculados à preocupação econômica de manter a atividade viável na região.

A pressão em relação à "disponibilidade de terra" tem elevado a competição entre a produção pecuária e de grãos por área. A análise das entrevistas evidenciou que a baixa produtividade da bovinocultura de corte é o motor dessa dinâmica de mudança do uso da terra, pois, comparativamente, a agricultura têm apresentado maiores rendimentos por hectare do que a pecuária, ainda que seja uma atividade com maior risco.

No entanto, os entrevistados também afirmam que essa situação não é inerente à pecuária, que poderia competir, em termos de rentabilidade, com a agricultura desde que a produtividade ultrapassasse a faixa de 18 a 20 arrobas por hectare. Para os entrevistados, o que hoje faz com que a agricultura obtenha maiores rendimentos por área que a pecuária é o nível de investimento por hectare.

Observa-se um consenso em torno do "perfil tradicional do pecuarista" como gargalo para avanços na produtividade e sustentabilidade. Ainda que o uso de tecnologias venha crescendo e a atividade esteja se modernizando, a aversão a risco e a grande cautela em realizar investimentos limitam a visão de longo prazo do segmento produtivo, resultados que estão em consonância com o exporto por Santos et al.[26].

A percepção dos agentes entrevistados corrobora o exposto por Dias-Filho[ ${ }^{[1]}$ em relação à tradição de baixo investimento no uso de insumos, tecnologia e mão de obra na atividade, se desdobrando em formação e manejo insuficientes das pastagens e em baixa produtividade por hectare. A baixa produtividade, por sua vez, se reflete em menor rentabilidade, o que limita os investimentos, como em um ciclo vicioso, tal qual descrito por Blum[40]. Para o autor, a falta total ou parcial de apenas um dos fatores produtivos (como acesso e manutenção da terra, mão de obra, capital financeiro, capacidade empresarial, etc.) limita o uso de tecnologia no processo produtivo. Como resultado, a produção não é eficiente e os custos por arroba produzida não diminuem.

Desse modo, o retorno financeiro é baixo, o que limita a capacidade de investimento na atividade - levando à continuidade do uso de baixa tecnologia no processo produtivo. Ou seja, pode-se dizer que é instaurado um ciclo vicioso de vulnerabilidades que compromete a permanência do produtor na atividade.

Mesmo assim, os entrevistados destacaram o "baixo risco" da bovinocultura de corte em comparação com a agricultura, o qual estimula a permanência de produtores na atividade mesmo em condições de baixa competitividade, assim como observado por Santos et al.[26]. Esses autores explicam que, ainda que a rentabilidade seja baixa e comprometa a sustentabilidade econômica de médio e longo prazo, dificilmente o pecuarista encontra-se em situação de falência, como acontece com agricultores em anos de adversidades climáticas.

Assim, "falta de investimentos" e "baixa rentabilidade" são conceitos intrinsicamente atrelados pelos entrevistados e culminam, em última instância, em péssimos indicadores produtivos e econômicos. No que diz respeito às preocupações econômicas que impulsionam o aumento de produtividade, destaca-se a necessidade de reduzir custos e de obter maior competitividade. A viabilidade de longo-prazo do negócio é entendida como sustentabilidade. Do lado social, destaca-se a dificuldade em obter mão-de-obra qualificada e as dificuldades em relação à sucessão familiar e êxodo rural.

Outros gargalos importantes para o aumento da produtividade dizem respeito ao "acesso a capital' para adotar tecnologias e sistemas produtivos mais vantajosos. Não se trata de desenvolvimento de novas tecnologias, mas sim de trabalhar condições de implementação.

Nesse sentido, a análise das entrevistas mostrou que a questão da "gestão da propriedade" é fundamental na percepção dos agentes. Para eles, trata-se principalmente de monitorar custos de produção e índices zootécnicos, aplicando conceitos de administração e de gestão estratégica. Esta 
prática implica numa mudança de paradigma, de uma gestão da atividade baseada em custos e não em receita.

Outro ponto levantado pelos entrevistados é a necessidade de um "manejo alimentar mais eficiente", com especial atenção para suplementação extra pasto e para o manejo das pastagens. A necessidade de o pasto ser compreendido pelo pecuarista como uma cultura é latente. Tendo em vista os desafios de aumento de produtividade e sustentabilidade, os entrevistados citaram práticas importantes como adubação, rotação de pastagens e uso de variedades mais resistentes às doenças. Para os entrevistados, é essencial que o pecuarista foque seus esforços em melhorar a qualidade do solo.

Nesse sentido, citaram os benefícios da ILP/ILPF como práticas que possibilitariam elevar a produtividade por área e aumentar a competitividade. De modo geral, ILP/ILPF foram chamadas de "tendência" no que se refere à "incorporação de sustentabilidade no sistema produtivo". Além da qualidade do solo, os entrevistados também mencionaram bem-estar animal e qualidade de vida dos pecuaristas ao passo que o sistema eleva a eficiência produtiva e proporciona maior valor agregado à produção.

As entrevistas revelaram que, na percepção dos agentes, o aumento da produtividade, a ideia de sustentabilidade e a ILP/ILPF são entendidos, principalmente, pelo retorno financeiro que propiciam no longo prazo. Cabe ressaltar, que em relação à ILPF, alguns entrevistados fizeram ressalvas sobre a viabilidade econômica da floresta. Para eles, por ser um investimento de prazo mais longo, o modelo produtivo ainda carece de dados que comprovem sua maior rentabilidade.

Os benefícios ambientais da prática foram considerados "mais um ponto positivo" pelos entrevistados. Por outro lado, os entrevistados reconhecem que a ILP/ILPF são modelos ambientalmente mais adequados e que essa visão pode se fortalecer no futuro. Também avaliaram que a adoção dos sistemas integrados vem crescendo, fomentada pelo compartilhamento de experiências positivas de outras pessoas. Por outro lado, a dificuldade de investimentos e de gestão nesse sistema ainda impedem sua popularização, assim como observado por Balbino, Barcellos e Stone [33].

A principal percepção dos entrevistados é de que o grande desafio da bovinocultura de corte é justamente interromper o ciclo vicioso de baixa produtividade por meio de uma mudança de paradigma produtivo que também é cultural. $\mathrm{Na}$ opinião dos agentes, a atividade tem evoluído consideravelmente e muitos produtores já têm o entendimento desses gargalos produtivos, buscando em diversas frentes superá-los - principalmente com foco em aumentar competitividade num mercado cada vez mais disputado. Aqueles que ainda não compreendem o panorama maior da atividade - a necessidade de otimizar o uso de recursos e aumentar a produtividade por área - na opinião dos entrevistados, serão forçados a deixa-la no médio longo-prazo.

Tendo em vista o enquadramento da Nova Economia Institucional, observa-se que o conceito de sustentabilidade não é compreendido e considerado em suas múltiplas dimensões, o que reforça o paradigma atual de exploração. As preocupações acerca da sustentabilidade para agentes do setor se justificam e se iniciam na esfera econômica. A busca por maior rentabilidade num contexto de limitação de área impulsiona a tomada de decisão para sistemas produtivos que garantam melhor competitividade no longo prazo. As esferas sociais e ambientais estão fragilizadas nessa óptica.

Motivados pela sustentabilidade econômica, apontam a ILP/ILPF como tendência para elevar a produtividade. É interessante, contudo, destacar que, ainda que não atribuam essa escolha às questões ambientais e sociais, a adoção da ILP/ILPF pode se desdobrar em possíveis benefícios nessas outras esferas. Nesse sentido, a prática pode fortalecer a compreensão e implantação da sustentabilidade em suas múltiplas dimensões.

\section{CONSIDERAÇÕES FINAIS}

Atender à crescente demanda por carne bovina é um enorme desafio para o atual sistema alimentar global e o Brasil assume um papel estratégico neste contexto. A bovinocultura de corte teve sua importância na ocupação do território 
brasileiro, mas se consolidou por meio de sistemas produtivos tradicionalmente de baixa produtividade o que associa a atividades a importantes impactos ambientais, como é o caso do desmatamento.

Nesse contexto, o debate acerca da segurança alimentar e nutricional ganha força, pois a insustentabilidade dos sistemas produtivos se reflete, também, na vulnerabilidade alimentar. Dessa forma, é preciso repensar os sistemas de produção da bovinocultura de corte e isso requer, igualmente, transformações no seu ambiente institucional.

Este trabalho constatou que a percepção de agentes da cadeia da bovinocultura de corte se alinha com a literatura no que diz respeito à necessidade imediata de se aumentar a produtividade dos sistemas produtivos no Brasil - fator identificado como o maior desafio da cadeia. Para os entrevistados, a promoção da sustentabilidade depende da elevação da produtividade por área, o que diminuiria a necessidade da expansão da fronteira agrícola.

No entanto, o conceito de sustentabilidade não é compreendido em suas múltiplas dimensões. A motivação em se elevar a produtividade por hectare é manter a atividade competitiva na região, tendo em vista a menor disponibilidade de terra, em virtude da disputa por área agricultável por outras culturas. Assim, a percepção de sustentabilidade ocorre primeiramente na esfera econômica, direcionando a tomada de decisão na busca de sistemas produtivos que garantam rentabilidade no longo prazo.

A crescente competitividade e globalização dos mercados têm imposto pressões para redução de custos, ainda mais diante da intensa disputa de terras com a produção de grãos. Para os entrevistados, a pecuária poderia competir, em termos de rentabilidade, com a agricultura desde que a produtividade aumentasse. Para eles, o que faz com que a agricultura obtenha maiores rendimentos é o nível de investimento e a cultura empresarial do agricultor. Ainda que o uso de tecnologias venha crescendo, e a pecuária esteja se modernizando, a falta de visão de longo prazo, aliado ao perfil tradicional do pecuarista, aversão a risco e grande cautela em realizar investimentos foram pontos enfatizados como limitantes na cadeia da bovinocultura de corte.
Os entrevistados apontam que a ILP é considerada uma tendência para o setor e que sua adoção se pauta nos benefícios associados, principalmente, à produtividade e rentabilidade. A ILPF também é considera uma tendência, mas os entrevistados destacaram que ainda existem pontos relacionados à viabilidade econômica que necessitam de maiores estudos. Os benefícios sociais e ambientais dessas práticas não são drivers de sua implantação, sendo considerados ganhos "adicionais".

Dessa forma, o estudo conclui que o conceito de sustentabilidade da produção é entendido pelos produtores fundamentalmente sobre a ótica econômica. A percepção em relação às esferas sociais e ambientais da sustentabilidade é fragilizada, fato que reforça o atual ambiente institucional da atividade.

Por outro lado, os agentes entrevistados reconhecem que a adoção e popularização da ILP e ILPF contribuem para o fortalecimento de alternativas ambientalmente mais adequadas. As sinergias produtivas dos sistemas de integração ILP/ILPF podem se configurar, portanto, como "portas de entrada" para o entendimento e valorização da sustentabilidade em suas múltiplas dimensões trazendo benefícios para a garantia da segurança alimentar e nutricional no longo prazo.

Por fim, reforça-se a necessidade da mudança do paradigma produtivo na bovinocultura de corte, o qual se estrutura e também é estruturado pelo seu ambiente institucional. Uma vez que as instituições definem as combinações de risco e recompensa que podem ser construídas com os recursos disponíveis na economia, é preciso elaborar mecanismos que incentivem a adoção de práticas ambientalmente mais adequadas. $\mathrm{Na}$ esfera produtiva, os principais desafios se concentram em captar recursos para financiamento e elevar o nível de gestão da propriedade.

\section{REFERÊNCIAS}

[1] Centro de Estudos Avançados em Economia Aplicada. PIB do Agronegócio Brasileiro [Internet]. 2017 [Acesso em 27 jun 2018]. Disponível em: https://www.cepea.esalq.usp.br/br/pib-do-agronegociobrasileiro.aspx 
[2] United States Department of Agriculture (USDA). Livestock and Poultry: World Markets and Trade [Internet]. 2018 [Acesso em 25 jun 2018]. Disponível em: https://apps.fas.usda.gov/psdonline/circulars/livestock_po ultry.pdf

[3] Silva PP. A conversa entre a cozinheira e o cordon bleu: breve reflexão sobre a cozinha e a gastronomia no Brasil. In: Miranda DS, Cornelli G (org.) Cultura e Alimentação: saberes alimentares e sabores culturais. São Paulo: SESC; 2007.

[4] Associação Brasileira de Proteína Animal (ABPA) [Internet]. [Acesso em 10 jul 2018]. Disponível em: http://abpa-br.com.br

[5] Carvalho TB, Bacchi MRP. Estudo da elasticidade-renda da demanda de carne bovina, suína e de frango no Brasil. In: 35o Encontro Nacional de Economia, 2007; Recife. Recife: ANPEC; 2007.

[6] Brasil. Lei no 11.346, de 15 de setembro de 2006 [Internet]. Diário Oficial da União. 2006 set. 15. [Acesso em 11 jul 2018]. Disponível em: http:/ /www.unipac.br

[7] Custódio MB, Furquim NR, Santos GMM, Cyrillo DC. Segurança alimentar e nutricional e a construção de sua política: uma visão histórica. Segur Aliment Nutr. 2011;18(1):1-10.

[8] FAO - Food and Agriculture Organization of the United Nations. World Agriculture Towards 2030/2050 - The 2012 Revision. ESA Working Paper № 12-03, 154 p, Rome, FAO [Internet]. 2012 [Acesso em 01 mar 2018.] Disponível em: http://www.fao.org/docrep/016/ap106e/ap106e.pdf

[9] Michelini J. A pecuária bovina de corte no Brasil: significados, contradições e desafios em busca da sustentabilidade [tese]. São José dos Campos: Instituto Nacional de Pesquisas Espaciais; 2016.

[10] De Zen S, Santos MC. Demanda por carne está ao alcance do Brasil! Revista DBO - a revista de negócios da pecuária. 2015: 18.

[11] Dias-Filho MB. Degradação de pastagens: processos, causas e estratégias de recuperação. Belém: Embrapa Amazônia Oriental; 2011.

[12] Herrero M, Thornton PK. Livestock and global change: Emerging issues for sustainable food systems. Proceedings of the National Academy of Sciences. 2013: 110(52): 2087820881.
[13] Comissão Mundial sobre Meio Ambiente e Desenvolvimento: Nosso Futuro Comum. Rio de Janeiro: FGV; 1988.

[14] Brasil. Ministério da Saúde. Guia alimentar para a população brasileira, Brasília: Ministério da Saúde; 2014.

[15] Tobler C, Visschers VHM, Siegrist M. Eating Green. Consumers' Willingness to Adopt Ecological Food Consumption Behaviors. Appetite. 2011; 57(3):674-682.

[16] Kluthcouski J, Cordeiro LAM, Vilela L, Marchão RL, Salton JC, Macedo MCM, et al. Conceitos e modalidades da estratégia de Integração Lavoura-PecuáriaFloresta [Internet]. Brasília, DF: Embrapa, 2015 [Acesso em 17 jul 2018]. Disponível em: https://ainfo.cnptia.embrapa.br

[17] Prado Júnior C. Formação do Brasil contemporâneo. São Paulo: Editora Brasiliense; 1945.

[18] Furtado C. Formação Econômica do Brasil. Rio de Janeiro: Editora Fundo de Cultura S/A; 1964.

[19] Correa VHC, Belik W. A expansão recente e a ocupação de novas áreas pelas produções de soja, cana-deaçúcar e pecuária bovina no Centro-Oeste. In: Anais do 51ㅇ Congresso da Sociedade Brasileira de Economia, Administração e Sociologia Rural (SOBER), 2013; Belém. Belém: SOBER; 2013.

[20] Domingues MS, Bermann C. O arco de desflorestamento na Amazônia: da pecuária à soja. Ambient. soc. [Internet]. 2012 [Acesso em 25 fev 2018]; 15(2): 1-22. Disponível em: http://www.scielo.br

[21] Dias-Filho MB. Uso de Pastagens para a Produção de Bovinos de Corte no Brasil: Passado, Presente e Futuro. Belém: Embrapa Amazônia Oriental; 2016.

[22] Fernandes VB, Morgan TA. Debilidade da governança de terras no Brasil: o caso do Pará. In: FAO/SEAD. Governança de terras: da teoria à realidade brasileira. Brasília: FAO/SEAD; 2017.

[23] Scarborough P, Appleby PN, Mizdrak A, Briggs ADM, Travis R, Bradbury KE, et al. Dietary greenhouse gas emissions of meat-eaters, fish-eaters, vegetarians and vegans in the UK. Climatic Change. 2014; 125(2):179-192.

[24] SEEG. Sistema de Estimativas de Emissões e Remoções de Gases de Efeito Estufa (SEEG) Observatório do Clima (OC). Base de Dados de Estimativa de Emissões de Gases de Efeito 70 Estufa no Brasil 1970- 
2016 - SEEG 5.0 [Internet]. 2018 [Acesso em 20 jun 2018]. Disponível em: http://plataforma.seeg.eco.br

[25] North DC. Five propositions about institutional change. In: Knight J, Sened I (org.). Explaining social institutions. Ann Arbor: Michigan Universiy Press; 1995.

[26] Santos MC, Belik W, De Zen S, Almeida LH. A rentabilidade da pecuária de corte no Brasil. Segur Aliment Nutr. 2014; 2:505-517.

[27] Silva CAB, Batalha MO. Estudo sobre a eficiência econômica e competitividade da cadeia agroindustrial da pecuária de corte no Brasil. Brasília: IEL, CNA e SEBRAE; 2000.

[28] Martha GB, Alves E, Contini E. Land-saving approaches and beef production growth in Brazil. Agricultural Systems. 2012; 110: 173-177.

[29] Strassburg BBN, Latawiec AE, Barioni LG, Nobre CA, Silva VP, Valentim JF, et al. When enough should be enough: improving the use of current agricultural lands could meet production demands and spare natural habitats in Brazil. Global Environmental Change. 2014; 28:84-97.

[30] Vedana MB, Vieira ETV, Itavo LCV. Produção Integrada: Possibilidade de Alimentos Seguros e de Qualidade. Agro em questão - Revista de Iniciação Científica da Faculdade CNA. 2017; 1(I):112-126.

[31] Corsi M, Goulart R. O sistema de produção de carne e as exigências da sociedade moderna. In: Anais do Simpósio sobre manejo da pastagem, 2006; Piracicaba. Piracicaba; FEALQ; 2006.

[32] Balbino LC, Cordeiro LAM, Porfirio-da-Silva V, Moraes ADE, Martinez GB, et al. Evolução tecnológica e arranjos produtivos de sistemas de Integração lavourapecuária-floresta no Brasil. Brasília (DF): Pesquisa Agropecuária Brasileira; 2011.

[33] Balbino L, Barcellos AO, Stone LF. Marco referencial: integração lavoura-pecuária-floresta (ILPF). Brasília (DF): ILPF; 2011.

[34] Crespolini M, Tufani M, Ermita OP, Luna I. Desafios e Oportunidades da Integração Lavoura-Pecuária em Rondônia: um estudo de caso da Fazenda Quatro Maravilhas. In: Anais do 56ㅇ Congresso da Sociedade Brasileira de Economia, Administração e Sociologia Rural (SOBER), 2018; Campinas. Campinas; SOBER; 2018.
[35] Organização Mundial das Nações Unidas no Brasil [nternet]. A cúpula. 2002 [Acesso em 28 ago 2018]. Disponível em: https:// nacoesunidas.org/pos2015/cupula

[36] Engel JF, Blackwell RD, Miniard PW. Comportamento do Consumidor. Rio de Janeiro: LTC Editor; 2000.

[37] Maltz E, Kohli AK. Market intelligence dissemination across functional boundaries. Journal of Marketing Research. 1996; 33: 47-61.

[38] Cooke P. Regional innovation systems - an evolutionary approach. In Cooke P, Heidenreich M, Braczyk HJ. Regional Innovation Systms. The role of governance in a globalized world. London: Routledge; 2004.

[39] Bernard HR. Research Methods in Anthropology: qualitative and quantitative approaches. Plymouth: AltaMira Press; 2011.

[40] Blum R. Agricultura Familiar: estudo preliminar da definição, classificação e problemática. In: Tedesco JC. (org.). Agricultura Familiar: Realidades e Perspectivas. Passo Fundo: EDIUPF; 2001. 